\title{
ResearchOnline@JCU
}

This is the author-created version of the following work:

Pillay, Neville, and Rymer, Tasmin L. (2020) Sons benefit from paternal care in African striped mice. Developmental Psychobiology, . (In Press)

Access to this file is available from:

https://researchonline.jcu.edu.au/65012/

(c) 2020 Wiley Periodicals.

Please refer to the original source for the final version of this work:

https://doi.org/10.1002/dev.22050 


\section{Sons benefit from paternal care in African striped mice}

2

3 Running head: Sons benefit from paternal care

4

5 Neville Pillay ${ }^{*}$ and Tasmin Lee Rymer ${ }^{1,2,3}$

6

$7{ }^{1}$ School of Animal, Plant and Environmental Science, University of the Witwatersrand,

8 Private Bag 3, WITS 2050, Johannesburg, South Africa

$9{ }^{2}$ College of Science and Engineering, James Cook University, P. O. Box 6811, Cairns, QLD

10 4870, Australia; E-Mail: Tasmin.Rymer@jcu.edu.au

$11{ }^{3}$ Centre for Tropical Environmental and Sustainability Sciences, James Cook University, P.

12 O. Box 6811, Cairns, QLD 4870, Australia

13

14 * Author to whom correspondence should be addressed; E-Mail: Neville.Pillay@wits.ac.za

15 Tel.: +27-11-717-6459; Fax: +27-11-717-6494

16

17 ACKNOWLEDGEMENTS

18 We thank our research assistants for their help with data collection. We also thank the staff at

19 the Milner Park Animal Unit for technical assistance. We received funding from the

20 University of the Witwatersrand and the National Research Foundation (Grant number:

21 2053514). The authors declare no conflict of interest. The comments of two anonymous referees improved the quality of our manuscript. 


\section{Abstract}

27 Mammalian paternal care is rare and is often linked to enhanced fitness under particular ecological conditions. The proximate consequences of paternal care on offspring are lacking, however. Here, we tested whether levels of paternal care predict the behavioural, cognitive and physiological development of sons in the naturally paternal African striped mouse (Rhabdomys pumilio). We focused on sons raised in two treatments: biparental (both parents) or uniparental (mother alone) families. We recorded levels of interactions between pups with both parents, and later assessed the behaviour, cognition and physiology of sons at three developmental stages: juvenile, sub-adult and adult (sexual maturity). Sons from biparental families showed (i) reduced anxiety as juveniles; (ii) greater exploration and social interaction at different stages; (iii) better cognition; and (iv) reduced corticosterone concentrations than sons from uniparental families. In contrast, sons from uniparental families showed greater levels of paternal care, although prolactin concentrations did not differ between treatments. Paternal care in striped mice enhances fitness of males. Here, we also show that sons benefit psychologically and physiologically through interactions with their fathers. However, sons also trade-off such benefits against their own paternal care behaviour, suggesting that fathers influence the development of their son's phenotype in complex ways.

Keywords: Cognition; Fitness; Hormones; Male parental care; Rhabdomys; Rodent; Tradeoff 


\section{INTRODUCTION}

Mammalian paternal care, defined as any direct or indirect nongametic investment made by the father post-fertilisation that benefits his offspring (Dewsbury, 1985; Woodroffe \& Vincent, 1994), is rare, occurring in only $5-10 \%$ of species (Wright, 2006). Paternal care is an evolved behaviour, modulated by neuroendocrine processes (e.g. prolactin, Schradin \& Anzenberger, 1999), which has a genetic basis (Rymer \& Pillay, 2011a) and may be epigenetically regulated by parental effects acting during an individual's ontogeny (Braun \& Champagne, 2014). The occurrence of paternal care in several mammalian lineages suggests some fitness-related benefits from providing (by the father) or receiving (by the offspring) care (Rymer \& Pillay, 2018).

Paternal care, like maternal care, may contribute directly to offspring survival, growth and/or cognitive and behavioural development (Gubernick \& Teferi, 2000; McCarty \& Southwick, 1977; Outscharoff, Helmeke, \& Braun, 2006; Wright, 2006). These effects are particularly discernible during the ontogeny of anxiety-like and social behaviours and cognition (Braun \& Champagne, 2014). For example, male California mice (Peromyscus californicus) that experienced high levels of retrieval by their fathers were more aggressive in resident-intruder tests (Frazier et al., 2006), whereas young mandarin voles (Microtus mandarinus) that experienced paternal deprivation were more anxious in an open field test (Jia et al., 2009). Furthermore, increased paternal care during development resulted in better object recognition and spatial memory in California mice (Bredy et al., 2004), whereas paternal deprivation resulted in impaired social recognition in prairie voles (Microtus ochrogaster; Prounis et al., 2015).

Paternal care may also influence the physiological development of offspring, leading to changes in behaviour and cognition. For example, mandarin voles that experienced paternal deprivation showed higher corticosterone concentrations and lower play-fighting, which is 
apparently a prelude to aggression in adulthood (Wang et al., 2012). Finally, by providing paternal care, males may also indirectly affect the physical, behavioural, cognitive and physiological development of offspring via alterations to female maternal care. For example, female rock cavies (Kerodon rupestris) increase their investment in offspring when a mate is absent, which has a concomitant effect on the growth of young: young raised by mothers only gain more weight than sons raised by both parents (Tasse, 1986).

The proximate factors underlying the expression of paternal care have been relatively well studied, but a broader understanding of the proximate outcomes in offspring benefitting from paternal care is lacking. Indeed, few studies have focused on how paternal care might be impacting aspects of offspring development (physiological, cognitive and behavioural) in the same subjects, while also considering the social environment in which offspring are raised (but see Agarwal et al., 2020). The African striped mouse (Rhabdomys pumilio) is a useful model for understanding the proximate consequences of paternal care because males from a population in the Succulent Karoo of South Africa are naturally paternal (Schradin \& Pillay, 2004). The neuroendocrine mechanisms affecting the expression of paternal care (e.g.

Schradin, 2008; Schradin \& Pillay, 2004), as well as the ontogeny and function of paternal care (e.g. Rymer \& Pillay, 2011b; Rymer, Schradin \& Pillay, 2008), have been well studied in this species.

African striped mice from the Succulent Karoo are socially flexible and facultatively group-living, which is contingent on female responses to population density. When population density is low, females prefer to nest alone to reduce the costs associated with reproductive competition, such as increased female-female aggression (Schoepf \& Schradin, 2012) and infanticide (Schradin, König, \& Pillay, 2010). Females fully compensate for a lack of care provided by a mate when they raise young alone (Rymer \& Pillay, 2011b). At this time, males will generally adopt a solitary roaming strategy, seeking mating opportunities and 
101 providing no paternal care (Schradin et al., 2009), although some males will remain with a single female, providing paternal care. As population density increases, breeding sites become limited and females often become constrained to nest in small groups (Schradin \& Pillay, 2004; Schradin et al., 2010). Males may then become territorial dominant breeders that show paternal care (Schradin \& Pillay, 2004). Consequently, uniparental, biparental and family units occur naturally in this population. enhance the development and growth of their offspring, most likely by providing thermoregulatory benefits (Schradin \& Pillay, 2005), and fathers provide social learning

110 opportunities for their young in response to novel food (Rymer et al., 2008). Jones, Mason \&

111 Pillay (2010) found that offspring raised by both parents showed lower levels of abnormal 112 repetitive behaviour (e.g. stereotypic behaviour) than offspring raised by mothers alone.

113 However, Rymer \& Pillay (2011b) found that sons raised by mothers alone showed higher

114 quality care to their own offspring than sons raised by both parents. Thus, although striped

115 mouse fathers benefit offspring growth, paternal care might have non-genetic consequences

116 on the paternal care behaviour of sons later. Whereas these findings collectively demonstrate

117 the impact fathers have on the general behavioural development of their offspring, the

118 influence of fathers on the cognitive and physiological development of their sons remains

119 unknown.

120 We investigated whether and how paternal care by male African striped mice predicted

121 the behavioural, cognitive and physiological ontogeny of their sons. We ascertained the 122 development of sons from two different social environments (mother and father present vs. 123 mother only) at different life stages from juveniles to adults, allowing us to explore how a 124 present or absent father can lead to different developmental trajectories in their sons. We 125 expected that paternal care would have a positive effect on the behavioural, cognitive and 
126 physiological development of males. We made four predictions. 1. Sons raised by both

127 parents would be less anxious, both behaviourally and physiologically (i.e. lower

128 corticosterone concentrations), as suggested for mandarin voles (Jia et al., 2009; Wang et al.,

129 2012). 2. Sons raised by both parents would show greater exploratory and increased social

130 behaviour than sons raised by mothers only, as seen in California mice (Glasper, Hyer, \&

131 Hunter, 2018). 3. Sons raised by both parents would show enhanced memory, because

132 growing up in a family group affects spatial cognitive abilities in female African striped mice

133 (Pillay \& Rymer, 2015). 4. Since sons raised by both parents show reduced paternal care as

134 adults (Rymer \& Pillay, 2011b), they would display lower concentrations of prolactin, a

135 hormone associated with paternal care in numerous species (Schradin \& Anzenberger, 1999),

136 including striped mice (Schradin, 2008).

137

138

2. METHODS

139 We used F4-5 descendants of wild-caught parents from the Succulent Karoo (Northern Cape

140 Province, South Africa: 29.41.56 S, 18.1.60 E). They were housed at the University of the

141 Witwatersrand under partially controlled environmental conditions (14:10 light-dark cycle,

142 lights on at $05: 00 ; 20-24{ }^{\circ} \mathrm{C} ; 30-60 \%$ relative humidity). We established 48 parentally

143 experienced breeding pairs housed in glass tanks $(90 \times 30 \times 45 \mathrm{~cm})$. Tanks were furnished

144 with a plastic nest box $(15 \times 15 \times 15 \mathrm{~cm})$, wood shavings for bedding, hay for nesting

145 material, and an assortment of enrichment devices (e.g. cardboard tubes, dowel sticks, tissue

146 paper). Each mouse was provided with approximately $5 \mathrm{~g}$ millet or sunflower seeds and

147 Epol ${ }^{\mathrm{TM}}$ mouse cubes (Epol, Pretoria West, South Africa) and approximately $5 \mathrm{~g}$ fresh

148 fruit/vegetables daily. Seed was sprinkled throughout the cage to stimulate foraging

149 behaviour. Water was available ad libitum. 
The 48 pairs were randomly and equally assigned to one of two treatments: biparental, in which both parents raised their offspring to weaning at 21 days of age; and uniparental, in which the mother raised offspring alone until weaning. In the uniparental treatment, fathers were removed from the breeding tank at parturition and housed elsewhere in the breeding

154 facility.

We video-recorded the parental care behaviour of the father and mother separately (biparental) and the mother only (uniparental) every second day from postnatal day (PND) 2 to PND 10, whereafter young started independent exploration of the tank and thus were not confined to the nest. We recorded behaviours of parents to provide a quantitative value of parental investment received by pups in each treatment. All adults were uniquely marked with non-toxic hair dye for individual identity. Observations were made for $30 \mathrm{~min}$ continuously during the peak of striped mouse activity periods between 10:00 to 12:00 and again between 15:00 and 16:00, generating $300 \mathrm{~min}$ of data in total. To ensure minimal disturbance, nest boxes were positioned in a manner to video record behaviours inside the nest from outside the tank. We recorded the duration of the following behaviours (see Schradin \& Pillay, 2003) performed by mothers and fathers (biparental) and mothers only (uniparental): time spent in close proximity $(<2 \mathrm{~cm})$ of pups (designated near), grooming pups (including sniffing and licking) and huddling pups; we could not differentiate between nursing and huddling pups by mothers, so we pooled these data and classified them as huddling (Rymer \& Pillay, 2011b). We summed the data for each individual for the five days of sampling.

At weaning on PND 21, two sons per litter were randomly selected and housed together in plastic boxes $(30 \times 25 \times 25 \mathrm{~cm})$ with wire lids. They were maintained as described above.

173 All sons were marked with non-toxic hair dye for identification. We used only one brother

174 (test male) in experiments (below) but group housing of brothers initially provided social 
175 stability for males and reduced stress following separation from the family (Mackay, Rymer, \& Pillay, 2014). Test males were housed alone from PND 40, long after natural natal dispersal, which normally occurs around four weeks of age (Schoepf \& Schradin, 2012). treatment. Males were used in a series of experiments (Figure 1), covering different life 180 stages: the juvenile (PND 25), sub-adult (PND 45-50) and adult (PND 80-> 120; sexually mature) age categories (Brooks, 1982). At each stage, age-appropriate behaviours were tested, although some behaviours were tested in more than one age category (Figure 1). All experiments were conducted between 10:00 and 12:00. Behavioural scoring was conducted by trained assistants who were blind to the experiments. After each test (or dyadic encounter), the experimental apparatus and any objects used were washed with warm soapy water and $70 \%$ alcohol and allowed to air dry to remove residual odours of the previous occupant. Any wood shavings used were replaced.

\subsection{Experiment 1. Emotional response in a novel environment}

190 On PND 25, 45 and 80, we studied the emotional response of test males in open field tests.

191 All individuals were tested once at each age. Tests were conducted under fluorescent light (361 lux), staged in glass tank arenas (45 x $30 \mathrm{~cm}$ and $30 \mathrm{~cm}$ high) with wire mesh lids. Tanks had a thin layer of coarse wood shavings.

The test male was released into the centre of the arena using a small closed plastic carrier

$195(15 \times 10 \mathrm{~cm})$, which was washed between tests. Thereafter, its behaviour was video-recorded 196 for 10 min using a video camera mounted above the arena. Using the Ethovision XT video-

197 tracking software (Noldus, Netherlands; http://www.noldus.com), we created a $3 \mathrm{~cm}$

198 peripheral zone on the inside perimeter of the tank (Pillay, Rimbach, \& Rymer, 2016) and

199 recorded: (i) the duration of time spent by the test mouse in the centre and on periphery; and 
200 (ii) the number of transitions between the periphery to the centre and back to the periphery.

201 We discarded the first transition since test subjects were introduced into the centre of the arena. To assess anxiety, we analysed the time spent in the centre, as more time spent on the periphery indicates greater anxiety (Pillay et al., 2016).

\subsection{Experiment 2. Social interaction in dyadic encounters and corticosterone} measurements

207 On PND 47 and 88, we studied the social behaviour of individuals in dyadic encounters in a neutral arena. Dyads comprised of the test male and an unrelated age- and weight-matched stimulus male from our breeding colony. Males were tested with different dyad partners at each age.

Dyadic encounters were staged in glass tanks $(60 \times 30 \times 35 \mathrm{~cm})$ equipped with perforated

212 lids. Tanks had a $1 \mathrm{~cm}$ deep layer of wood shavings. Each tank was divided with an opaque

213 partition. The test and stimulus males were randomly placed on either side of the partition for

$2145 \mathrm{~min}$ to acclimate to the arena. The barrier was removed, and the behaviour of the dyad was

215 video recorded for $15 \mathrm{~min}$. The first minute of recording was discarded because of the

216 disturbance of removing the barriers. We recorded the frequency of allogrooming of the

217 stimulus male by the test male, duration of close body contract and aggression by the test

218 male (e.g. box, chase and/or tumble). One of us (NP) sat in the room to terminate dyads that

219 engaged in damaging fights, but aggression was mostly chases and occasionally boxes, and

220 no animals were harmed in the study. After encounters, dyads were examined for any injuries, but none was recorded. 


\subsection{Corticosterone assays}

226

227

228

229

230

231

232

233

234

235

236

237

On PND 88, after the dyadic encounters, we measured serum corticosterone concentrations from 12 randomly selected males per treatment $(n=24)$. We chose a subset of males because the blood sampling used was invasive and potentially stressful. These males were not used again in further experiments.

The males were anaesthetised with Isoflurane 20 min after dyadic encounters, and a blood sample of 200-500 $\mu 1$ was collected from the saphenous vein of one leg, a procedure that does not result in elevated corticosterone concentrations in laboratory mice (Mus musculus, ICR strain; Abatan, Welch, \& Nemzek, 2008). Males weighed $>60 \mathrm{~g}$ at testing, and the volume of blood collected was sufficient for analysis without long-term impact (Schradin et al., 2009). We timed blood collection to coincide with the peak of corticosterone release after dyads, which is estimated to be 30-40 min following a stress test in SpragueDawley rats (Rattus norvegicus, Cavigelli \& McClintock, 2003), and to control for circadian rhythm variation in hormone secretion. The time from anaesthesia to blood collection did not differ statistically between the biparental $(8.7 \pm 0.8 \mathrm{~min})$ and uniparental $(8.6 \pm 0.7 \mathrm{~min})$ males $[t(21.19)=-0.16, p=.874]$.

Blood samples were left at room temperature for one hour and then centrifuged twice for $10 \mathrm{~min}$ each. The resulting serum was isolated and frozen in aliquots of $20 \mu \mathrm{l}$ at $-20^{\circ} \mathrm{C}$.

Corticosterone analysis was performed using a commercial radioimmunoassay (RIA) kit (MP Biomedical Solon, Ohio). Intra-assay variability was 10.1\%; samples were analysed in one assay. All procedures were performed according to the manufacturer's instructions.

\subsection{Experiment 3. Short-term memory: recognition memory}

At PND 50, males were tested in novel object recognition tests, following Akkerman et al. (2012). Tests were conducted in the same glass tank arenas used in open field tests. The 
procedure comprised of three sessions: habituation, training and retention, each conducted approximately $24 \mathrm{~h}$ apart. During habituation sessions, a test male was provided with an opportunity to explore the arena for $10 \mathrm{~min}$. During training sessions, two identical plastic figurines ( $5 \mathrm{~cm}$ high $\mathrm{x} 3 \mathrm{~cm}$ wide) were placed $10 \mathrm{~cm}$ from either the left or right corners of the arena (the side on which each figurine was placed was alternated between tests). The figurines were $2 \mathrm{~cm}$ apart and held down with Prestik ${ }^{\mathrm{TM}}$ adhesive. We had 10 pairs of figurines, which were washed and used interchangeably between tests. A male was placed into the middle of the arena using a plastic carrier and its behaviour was recorded for $5 \mathrm{~min}$. Using the multiple-tracking module in Ethovision XT video-tracking software, we scored the duration that the test male spent investigating each object (i.e. touching the object or orientated towards the object up to a $1 \mathrm{~cm}$ away).

During retention sessions, test mice were again presented with two objects: one of the familiar objects used during training and a novel object of the same size but different in appearance. Individuals were allowed to explore the objects again for $5 \mathrm{~min}$, and we scored the time they spent investigating both objects.

The time spent investigating objects might be a function of exploratory tendencies. To counter this bias, we assessed five variables: (i) Et (explore training) - time spent with both identical sample objects $(\mathrm{O} 1+\mathrm{O} 2)$ during the training trial; (ii) Er (explore retention) - time spent with the novel object and familiar object $(\mathrm{N}+\mathrm{O})$ during the retention trial; (iii) $\mathrm{Da}-$ absolute difference between time spent with the novel object and sample object during the retention trial (N - O); (iv) $\mathrm{Nr}$ - relative time spent with the novel object $(\mathrm{N}-\mathrm{O}) /(\mathrm{N}+\mathrm{O})$ during the retention trial, providing a measure of discrimination of the novel object corrected for exploration; and (v) $\mathrm{Np}$ - proportion of time spent with the novel object during the retention trial $\mathrm{N} /(\mathrm{N}+\mathrm{O})$. 


\subsection{Experiment 4. Short-term memory: Spatial working memory in the Y maze}

276

277

At PND 83, we assessed the short-term memory ability of males using a closed Y maze test.

The Y maze choice apparatus was built of transparent plexiglass material and comprised of a start box $(36 \times 20 \mathrm{~cm}$, height $=16 \mathrm{~cm})$ connected by a Y maze (internal diameter $4.6 \mathrm{~cm} ; 22$ $\mathrm{cm}$ long arms) to two choice chambers (same size as the start box). The apparatus was placed in a white room with several extra-maze cues (i.e. chair, paintings on the wall).

The procedure comprised of a training phase and a testing phase. At the beginning of the training phase, the entrance to one arm leading a choice chamber was randomly selected and blocked off using an opaque disc. This was designated the novel arm. A male was placed in the start box that was blocked off from the rest of the maze using an opaque partition. After a 5 min habituation period, the partition was removed, and the male was allowed to explore the maze for $10 \mathrm{~min}$, excluding the novel arm. Thereafter, the male was removed from the maze and returned to its home cage. The test phase started one hour later when the barrier to the novel arm was removed. The male was returned to the start box for a 5 min habituation period, as for the training phase, and was then allowed to explore the entire maze, including the novel arm, for $10 \mathrm{~min}$. The behaviour of the male was video recorded from above and no observers were present in the room during training or testing.

We recorded the total number of arm entries (defined by half a body length in an arm), the number of alternations and the percent alternations. The number of alternations was calculated from the sequence of three different arm entries (e.g. arms 3, 1,2); repeated use of the arms (e.g. 2, 1,2) were not considered in alternation scores. The percent alternation was calculated using the formula: total number of alternations / number of arms entered $* 100$.

\subsection{Experiment 5. Paternal care and prolactin measurements}


299 At approximately PND 120, 12 males (i.e. those not sampled for corticosterone; above) per 300 treatment $(\mathrm{n}=24)$ were paired with unrelated, age-matched females from our colony. Breeding

301 pairs were established (as described above) and housed in glass tanks (46 x $30 \times 32 \mathrm{~cm}$ ). Pairs

302 were provisioned with food, water and enrichment (as described above).

303 Paternal care (parents were uniquely marked with non-toxic hair dye to identify fathers)

304 was recorded every second day from PND 2 to 10 for $1 \mathrm{~h}$ per day (as described above). We

305 also recorded litter size.

306

$307 \quad 2.7$ Prolactin assays

308 Blood samples were collected from all males that sired and raised offspring (biparental:

$309 \mathrm{n}=10$; uniparental: $\mathrm{n}=11)$ when litters were 11 days old. We waited until after pups started to

310 eat solid food (PND 10-11; Pillay, 2000) and paternal care observations were completed

311 before sampling prolactin in males to reduce the possibility of maternal aggression directed

312 towards males returned to the breeding cage after their removal, which would have

313 influenced paternal care (pers. obs.). Blood was collected between 09:00 and 11:00 as

314 described above for corticosterone analyses. However, stress can lead to increased prolactin

315 concentrations (Ziegler, Wegner, \& Snowdon, 1996). To minimise stress, males were

316 removed from the breeding tank, taken to an adjacent room and immediately anesthetised.

317 Blood was collected approximately $5 \mathrm{~min}$ later. The time from anaesthesia to blood collection

318 did not differ statistically between the biparental ( $8.2 \pm 0.8 \mathrm{~min})$ and uniparental $(9.8 \pm 0.8$

$319 \min )$ males $[t(18.95)=-1.36, p=.189]$. Males were then placed into holding cages and, once

320 they were awake and fully recovered (about 30 min later), they were then housed singly in

321 the breeding colony under the same conditions (as described above). 
Collected blood was transferred into an Eppendorf tube and kept at room temperature for isolated and frozen in aliquots of $20 \mu 1$ at $-20{ }^{\circ} \mathrm{C}$ for 1 month before analysis.

A commercial RIA kit for measuring rat prolactin was used (MP Biomedical Solon,

Ohio). All procedures were performed according to the manufacturer's instructions. Samples from all males were analysed in one assay, and the intra-assay variation was $10.2 \%$.

\subsection{Statistical analyses}

330 All analyses were performed using R studio (R version 4.00; http://www.R-project.org). All

331 data were tested for homogeneity of variances (Levene's test) and normality (Shapiro-Wilks

332 test). Non-normal data were transformed using the Box-Cox method (MASS package, Ripley et al., 2020). We used Welch's two-sample t-tests or analysis of variance (ANOVA) to analyse variables by treatment for most experiments. When tests were repeated at different ages (i.e. emotional responses and social interactions), linear models for repeated measures (lme4 package, Bates et al., 2020; car package, Fox et al., 2020) were used to analyse variables by treatment (fixed factor) and time (age at testing) for individuals (repeated measures). Pairwise contrasts (Tukey post hoc tests) were obtained for significant predictors (emmeans package, Lenth et al., 2020). The model-level significance was determined at $\alpha=$ 0.05 and all tests were two-tailed. Data are presented as mean $( \pm \mathrm{SE})$ throughout.

\section{Ethical Note}

343 This study complied with the current laws and regulations in South Africa, and the research

344 adhered to the ABS/ASAB guidelines for the ethical treatment of animals in research (Bee et al., 2020). Animals were provided with environmental enrichment, and the welfare of the

346 animals was monitored daily. The experimental procedures did not have any obvious 
negative effects on the welfare of the striped mice. Dyads were carefully monitored to prevent any fights; no physical harm occurred. At the end of the study, all experimental animals were kept as part of the breeding stock of the colony. Experimental procedures were approved by the Animal Ethics Screening Committee of the University of the Witwatersrand (AESC 2010/55/2A, 2012/13/3, 2013/18/2A).

\section{RESULTS}

\subsection{Parental care behaviours of mothers and fathers}

Fathers in the biparental treatment spent significantly more time near their pups $[F(2,69)=$ $6.56,69, p=.002]$ than their mates (biparental) and mothers alone (uniparental; Table 1). However, mothers raising their litters alone huddled $[F(2,69)=118.51, p<.001]$ and groomed $[F(2,69)=70.57, p<.001]$ their pups significantly more than either fathers or mothers in the biparental group (Table 1). The two groups did not differ significantly in their

361 litter sizes [biparental $=4.9 \pm 0.21 ;$ uniparental $=5.25 \pm 0.26 ; t(43.88)=-1.11, p=.274]$. (mothers alone) treatments showed that biparental groups spent significantly more time near pups than mothers alone $[t(28.68)=6.06, p<.001]$, whereas mothers raising pups alone groomed their pups significantly more than biparental groups $[t(27.74)=6.97, p<.001]$.

366 There was no significant difference between the groups for huddling pups $[t(38.68)=-0.72, p$ $367<.475 ;$ Table 1].

\subsection{Experiment 1. Emotional response in a novel environment}

370 Treatment $\left[\chi^{2}{ }_{1}=30.11, p<.001\right]$, age $\left[\chi^{2}{ }_{2}=467.20, p<.001\right]$ and treatment $*$ age $\left[\chi^{2}{ }_{2}=\right.$

$3718.36, p=.004]$ were all significant predictors of time spent in the centre of the arena. Juvenile 
males from the biparental treatment were significantly less anxious than juvenile males from

373 the uniparental treatment, spending 1.8 times more time in the centre of the arena (Figure 2a).

374 Time spent in the centre was similar between juvenile and sub-adult males from the

375 biparental treatment, whereas sub-adult males increased the time spent in the centre from the

376 juvenile to the sub-adult stage, although not significantly so (Figure 2a). Adult males from

377 both treatments spent the greatest amount of time in the centre, and there was no significant

378 difference between treatments for these males (Figure 2a).

Treatment $\left[\chi^{2}{ }_{1}=15.57, p<.001\right]$ and age $\left[\chi^{2}{ }_{2}=142.66, p<.001\right]$ were significant

380 predictors of the number of transitions made by test males between the periphery and the centre of the arena. Males from the biparental treatment made more transitions at all three life stages than males from the uniparental treatment (Figure 2b), and males from both treatments showed a graded increase in the number of transitions with age (Figure $2 \mathrm{~b}$ ). The interaction between treatment and age was not a significant predictor of the number of transitions made $\left[\chi^{2}{ }_{2}=4.79, \mathrm{p}=.091\right]$.

\subsection{Experiment 2. Social interaction in dyadic encounters and corticosterone}

measurements

389 The frequency of allogrooming was influenced by treatment $\left[\chi^{2}{ }_{1}=8.39, p=.004\right]$ and age $\left[\chi^{2}{ }_{1}=9.59, p=.002\right]$ but not treatment $*$ age $\left[\chi^{2}{ }_{1}=0.35, p=.555\right]$. Males from the biparental treatment showed 1.5 times more allogrooming than males from the uniparental treatment, and allogrooming by males in both treatments decreased in adult males compared to subadult males (Figure 3a).

Age $\left[\chi^{2}{ }_{1}=78.23, p<.001\right]$ and treatment $*$ age $\left[\chi^{2}{ }_{1}=11.52, p<.001\right]$ were significant predictors of the time spent sitting in close body contact, whereas treatment was not a significant predictor of close body contact $\left[\chi^{2}{ }_{1}=1.75, p=.186\right]$. Sub-adult males from the 
biparental treatment made the most body contact with dyad partners, followed by sub-adult males from the uniparental treatment (Figure 3b). Males from both treatments showed similar and reduced body contact with dyad partners when they were adults (Figure 3b).

Aggression was significantly affected by treatment $\left[\chi^{2}{ }_{1}=23.14, p<.001\right]$, age $\left[\chi^{2}{ }_{1}=\right.$ $130.25, p<.001]$ and treatment $*$ age $\left[\chi^{2}{ }_{1}=13.23, p<.001\right]$. Adult males from the biparental treatment were the most aggressive, whereas all other treatment and age combinations showed lower, but similar, levels of aggression (Figure 3c). Overall, males from the biparental treatment engaged in more social interactions, whether they were amicable (allogrooming, body contact) or aggressive, although behaviours changed with age. Adult males from the biparental treatment had significantly lower corticosterone concentrations $(715.96 \pm 61.78 \mathrm{ng} / \mathrm{ml})$ than males from the uniparental $(973.36 \pm 94.64$ $\mathrm{ng} / \mathrm{ml})$ treatment $[t(18.9)=2.28, p=.035]$.

409

\subsection{Experiment 3. Short-term memory: recognition memory}

411 In the training phase, there was no significant difference in the time that males from both

412 treatments spent exploring similar objects [Et; $t(40.8)=0.60, p=.551$; Figure 4a]. In

413 contrast, during the retention phase when a novel and familiar object was presented to the

414 males, those from the biparental treatment showed significantly greater levels of exploration

415 (Er) than males from the uniparental treatment $[t(42.4)=3.70, p<.001$; Figure 4a $]$. The

416 difference in the time spent with the novel object and familiar object (Da) was also

417 significantly higher in the biparental treatment than the uniparental treatment $[t(38.0)=4.41$, $418 p<.001$; Figure 4a]. When corrected for exploration, the time spent with the novel object

$419(\mathrm{Nr})$ was also significantly greater in the biparental treatment than the uniparental treatment

$420[t(35.9)=2.96, p=.005$; Figure $4 b]$, confirming the reduced investigation (Da) of the uniparental treatment. Finally, males from the biparental treatment spent a significantly 
greater proportion of time with the novel object $(\mathrm{Np})$ than males from the uniparental treatment $[t(35.9)=2.96, p=.005 ;$ Figure $4 \mathrm{~b}]$.

\subsection{Experiment 4. Short-term memory: Spatial working memory in the Y maze}

Alternation scores in the Y maze (i.e. the number of sequences made in the three different arms) did not differ significantly between males from the biparental and uniparental treatments $[t(42.5)=1.19, p=.241$; Figure 5]. However, males from the biparental treatment made significantly more arm entries into the $\mathrm{Y}$ maze than males from the uniparental treatment $[t(41.5)=3.12, p=.003$; Figure 5]. The percentage alternation did not differ significantly between males from the different treatments $[t(40.1)=0.17, p=.865$; Figure 5].

\subsection{Experiment 5. Paternal care and prolactin measurements}

Males from the uniparental treatment showed significantly greater levels of grooming $[t(9.21)$ $=2.69, p=.025]$ and huddling $[t(19.0)=-2.54, p=.020]$ of their pups than males from the biparental treatment (Figure 6). There was no significant difference in the time spent near pups between the treatments $[t(18.02)=0.33, p=0.746$; Figure 6]. Litter size was not significantly different between treatments $[$ biparental $=4.6 \pm 0.34$; uniparental $=4.7 \pm 0.38$; $t(18.9)=-0.25, p=0.801]$

Concentrations of prolactin did not differ significantly between males from the biparental $(20.80 \pm 1.05 \mathrm{ng} / \mathrm{ml})$ and uniparental $(22.64 \pm 1.61 \mathrm{ng} / \mathrm{ml})$ treatments $[t(16.9)=0.96, p=$ $0.353]$

\section{DISCUSSION}

Although paternal care is facultative in African striped mice from the Succulent Karoo, when males do care, they provide similar amounts of care to females (Rymer \& Pillay, 2011b), and 
447 show all the behavioral characteristics of females (e.g. grooming and huddling pups), apart

448 from lactation (Schradin \& Pillay, 2003). Paternal care by striped mice enhances offspring

449 development (Schradin \& Pillay, 2005) and fathers provide social learning opportunities for

450 their young (Rymer et al., 2008). Here, we provide evidence that paternal care by male

451 striped mice has important consequences for their young.

452 We investigated the influence of paternal care on the ontogeny of multiple phenotypes

453 (behavioural, cognitive and physiological) in their sons. We assessed the development of

454 males from two different social environments (mother and father present vs. mother only),

455 both of which naturally occur in striped mice from the Succulent Karoo. Our experimental

456 design allowed us to consider how early life experiences, with a present or absent father, lead

457 to different behavioural trajectories in their sons between treatments. Consistent with Rymer

458 \& Pillay (2011b), in the absence of fathers, mothers showed higher levels of grooming and

459 similar levels of huddling than both mothers and fathers raising pups together, indicating that

460 females are compensating for a lack of paternal care when fathers are absent.

461 We expected that paternal care would have a positive effect on the behavioural, cognitive

462 and physiological development of males. The presence of striped mouse fathers was

463 associated with reduced anxiety-like behaviour and increased exploration in the open field

464 test, but this was age-dependent. Sons raised by both parents were less anxious and more

465 exploratory as juveniles than sons raised by both parents, which is somewhat consistent with

466 the findings of Perkeybile, Griffin \& Bales (2013) for prairie voles, although juvenile prairie

467 voles that received more parental care were less anxious in the elevated plus maze, but not

468 the open field. Furthermore, we found that adult striped mouse sons were generally less

469 anxious than juveniles and sub-adults, regardless of treatment, which is contrary to CD-1

470 laboratory mice, where sub-adults were less anxious that both juveniles and adults (Macrì et

471 al., 2002). Interestingly, we found that treatment effects on anxiety dissipated with age, 
suggesting that paternal effects only mediate anxiety during early development. Males from the biparental treatment were more exploratory at all three life stages than males from the uniparental treatment, although males from both treatments showed a graded increase in exploratory behaviour with age. Our findings are consistent with those of California mice, where paternal deprivation resulted in decreased exploratory behaviour in the elevated plus maze (Glasper et al., 2018). Striped mice start to eat solid food around PND 10-11, and are generally weaned at PND 16 (Pillay, 2000), when they start leaving the natal nest on foraging trips. Striped mice are solitary foragers (Schradin \& Pillay, 2004), and, therefore, we suggest that less anxious, more exploratory juvenile striped mice benefit by spending more time foraging than more anxious, less exploratory juveniles, which would enable them to increase their energy reserves. That older mice were less anxious and more exploratory than younger mice suggest that younger mice are more circumspect as they start exploring and learning their new surroundings. Furthermore, we suggest that decreased anxiety and increased exploration in striped mice raised by both parents likely provides a competitive advantage into adulthood, since older male striped mice must search for both food and mates.

Sons raised by both parents engaged in greater social interactions in dyads than sons raised by their mothers alone. Sons from the biparental group engaged in more allogrooming and spent more time in body contact with a dyad partner than males from the uniparental group, which is consistent with prairie voles that receive high quality care from their fathers

491 (Perkeybile et al., 2013). In contrast, adult males from the biparental group were also more 492 aggressive than males from the uniparental group. Jia et al. (2009) found that males which experienced paternal deprivation were also less aggressive than males raised by both parents. In general, we found that positive social behaviours declined with age in striped mice, which is consistent with previous findings in striped mice in which both dominant group-living males and solitary roamer males were aggressive, with higher concentrations of testosterone, 
497 than younger philopatric helpers (Schradin et al., 2009), suggesting that male fighting ability, 498 and thus competitive ability, increases with age.

499 Increased corticosterone concentrations are positively associated with increased anxiety-

500 like behaviours in Sprague Dawley rats (Vallée et al., 1997) and African striped mice

501 (Mackay et al., 2014), suggesting that corticosterone concentrations can reflect anxiety. Adult

502 males from the biparental treatment had significantly lower corticosterone concentrations

503 than males from the uniparental treatment, indicating decreased anxiety in males raised by the

504 father and comparatively greater anxiety in males raised without their fathers. Similarly, in

505 California mice, reduced paternal grooming was associated with elevated corticosterone

506 concentrations (Frazier et al., 2006). Lower corticosterone is associated with aggressive

507 behaviour in several species (e.g. Clarke \& Faulkes, 1997; Leshner, 1980; Schuurman, 1980),

508 including white-footed mice (Peromyscus leucopus; Oyegbile \& Marler, 2006), but not

509 California mice (Oyegbile \& Marler, 2005). Corticosterone can suppress the secretion of

510 testosterone by inhibiting transcription of genes coding for biosynthetic enzymes in

511 testosterone (Hardy et al., 2005; Retana-Márquez et al., 2003). Likewise, testosterone can

512 have an inhibitory effect on corticosterone (Place \& Kenagy, 2000). This relationship

513 between high testosterone and low corticosterone concentrations has been previously

514 identified in both free-living and captive-born striped mice (Raynaud, Müller, \& Schradin,

515 2012; Raynaud \& Schradin, 2014). Male striped mice with higher testosterone concentrations

516 have larger home ranges (Raynaud et al., 2012) and are more aggressive to their immediate

517 neighbours that are likely to steal paternity from territorial males (Schradin, Schneider, \&

518 Lindholm, 2010). Consequently, males raised by both parents likely experience fitness

519 benefits associated with mating and reproductive success compared to males raised by

520 mothers only. 
Rymer \& Pillay (2011b) showed that striped mouse males from a uniparental treatment displayed significantly greater levels of paternal care towards their pups than males from a

523 biparental treatment. Again, we found that females compensate for a lack of paternal care 524 when raising young alone, resulting in their sons displaying higher levels of paternal care 525 than sons raised by both parents (i.e. from biparental pairs). The point to emphasise is that 526 differences between treatments was a matter of degree, in that the biparental treatment sons did show paternal care, but to a reduced extent, and were never neglectful or aggressive to the pups. In laboratory rats, high levels of maternal grooming and licking resulted in neuroendocrine alterations in offspring associated with reduced anxiety (Liu et al., 1997). It is

530 thus possible that the greater levels of grooming displayed by mothers in the uniparental 531 treatment resulted in sons displaying greater levels of paternal care. Whether this was due to reduced anxiety of the sons, as suggested by Liu et al. (1997), is unclear since these males did not display reduced anxiety in other contexts (e.g. open field tests). Our findings suggest that

534 the development and expression of paternal care in African striped mice could be regulated

535 by epigenetic mechanisms (e.g. DNA methylation and/or histone modification and/or

536 interactions with transposons and retrotransposons; Curley, Mashoodh \& Champagne, 2011;

537 Mashoodh \& Champagne, 2019), some of which may be activated through tactile stimulation provided by the mother. Alternatively, or in addition to, the development and expression of paternal care in African striped mice could be influenced by organisational and/or

540 activational hormonal effects (Elekonich \& Robinson, 2000), which might also be

541 epigenetically modulated. Organisational effects create permanent, irreversible changes in

542 neural substrates (i.e. neural pathways) during pre-natal or early postnatal development, and 543 activational effects modify neural activity in these pathways during adulthood (Elekonich \&

544 Robinson, 2000), both affecting behaviour. These hormonal effects are suggested to affect the 545 development of parental care and other behaviours in other rodents (e.g. California mice, 
546 Gubernick, Sengelaub, \& Kurz, 1993), as well as striped mice (e.g. Raynaud et al., 2012;

547 Rymer \& Pillay, 2013). However, the concentration of prolactin was not significantly higher

548 in males from the uniparental treatment even though they displayed more paternal care. It

549 appears that levels of prolactin in striped mice are not associated with levels of paternal care,

550 as was also suggested by Schradin \& Pillay (2004). Instead, prolactin most likely maintains

551 paternal care once initiated via interactions with pups, as seen in Djungarian hamsters

552 (Phodopus campbelli; Ma et al., 2005), regardless of the levels of care displayed. This is

553 supported by field studies, where territorial breeding male striped mice have higher

554 concentrations of prolactin than roaming males but only in the breeding season (Schradin,

555 2008), indicating that prolactin helps maintain paternal care, but is unlikely to function in its

556 initiation. Once prolactin concentrations reach a threshold level, paternal care behaviour will

557 occur. Thus, the differences in paternal behaviour between sons in biparental and uniparental

558 treatments might be related to other factors, such as reduced anxiety (as mentioned above).

559 Biparentally raised sons had better cognitive ability. Males in the biparental treatment

560 explored the novel object for longer than males from the uniparental treatment, which is

561 consistent with the findings of Bredy et al. (2004) for California mice. The novel object

562 recognition test is commonly used to investigate aspects of learning and memory in rodents

563 (Lueptow, 2017), and our study shows a positive effect of paternal care on the short-term

564 memory of striped mice. However, we found no significant treatment effect on the spatial

565 working memory of striped mice. The Y maze is used to assess spatial memory and

566 hippocampal integrity and relies on an animal's natural instinct to explore and discover novel

567 environments (Shin et al., 2016). There was no significant difference in alternation scores in

568 the Y maze, suggesting that the spatial memory was intact, and that paternal deprivation does

569 not necessarily lead to hippocampal impairments in striped mice. The fact that males from the

570 biparental treatment made more arm entries into the maze indicates that they are more 
exploratory in general, which is consistent with our findings in the open field. Food resources are patchily distributed, and often ephemeral in the Succulent Karoo (e.g. insect flushes occur after seasonal rains; Schradin, 2005). Consequently, whereas increases in spatial working memory in striped mice are unlikely to confer an advantage for locating these resources, striped mice that are more exploratory are more likely to gain access to these patchily distributed resources compared to less exploratory mice. This could be particularly beneficial for young striped mice that must invest heavily in their own growth and development when they start to eat solid food.

We showed that altering the early rearing parental environment leads to different trajectories in a suite of behavioural, cognitive and physiological phenotypes of males. Such developmental plasticity leading to different developmental trajectories and phenotypes are well known. For example, the developmental trajectory of cockroaches (Diploptera punctata) was phenotypically plastic, dependent on prenatal and postnatal maternal care, as well as the postnatal social environment when males were present (Holbrook \& Schal, 2004). Moreover, a growing number of studies (e.g. Jonsson \& Jonsson, 2014) suggest that phenotypic plasticity, as a consequence of the early life environment and an individual's experiences, shapes the development of cognition, behaviour and personality, and alters stress responsiveness (e.g. Gudsnuk \& Champagne, 2011). Consequently, we suggest that striped mouse fathers have a modulating effect on offspring behavioural, cognitive and physiological development, such that offspring follow different ontogenetic trajectories based on early social interactions and the experience of paternal care.

Numerous studies on multiple taxa have shown paternal care has a positive effect on the reproductive success of fathers (e.g. California mouse, Cantoni \& Brown, 1997; spotless starling (Sturnus unicolor), Moreno et al., 1999); painted greenling (Oxylebius pictus), DeMartini, 1987); pine engraver beetles (Ips pini), Robertson, 1998). Similarly, several 
studies have shown that recipients of paternal care have better survival (e.g. California mice,

597 Wright \& Brown, 2002; glass frogs (Hyalinobatrachium orientale), Lehtinen, Green \&

598 Pringle, 2014; three-spined sticklebacks (Gasterosteus aculeatus), McGhee \& Bell, 2014). A

599 meta-analysis of 31 studies, including mammals, birds, fish, spiders and insects, found that

600 bolder, more aggressive individuals had greater reproductive success, and that more

601 exploratory, more aggressive individuals had greater survival (Smith \& Blumstein, 2008).

602

However, there was also a trade-off between boldness (e.g. greater exploratory behaviour)

603

and survival, with bolder individuals having lower survival (Smith \& Blumstein, 2008).

Although we did not find an effect of parental treatment on litter size in our study, most

likely because optimal conditions in captivity reduce the energetic constraints associated with reproduction (Brown, 1993), our findings provide compelling evidence that the fitness of sons is likely enhanced in multiple ways by paternal provisioning, since sons raised by both parents were more aggressive and more exploratory, which could lead to increased reproductive success. However, our results also show a trade-off between current and future

610 fitness. Whereas sons raised by both parents benefit from potential enhancements to foraging 611 and competitive ability, these same sons also demonstrate lower paternal care, which could impact their sons' development and concomitant fitness, growth and survival.

613 Collectively, our findings indicate that sons gain direct behavioural, cognitive and

614 physiological benefits by being raised in a social unit with their fathers. Sons raised with their

615 fathers were less anxious, showed greater exploration, were more aggressive as adults and

616 showed enhanced short-term memory. Yet, sons raised by both parents showed reduced

617 paternal care, at least in the first litters, compared to sons raised by their mothers only.

618 Whether these phenotypic modifications are syndromic and represent a composite

619 behavioural trajectory, or are individually defined trajectories for each phenotype, requires

620 further testing. In conclusion, we demonstrated in a naturally paternal species that fathers 
621 alter the developmental trajectory of the sons, potentially enhancing their sons' and their own

622 fitness. Thus, although paternal care is rare in mammals, its impact can, nevertheless, be

623 profound, as demonstrated here in striped mice. Future studies should investigate how the

624 effects of paternal care through the phenotypes measured here enhances fitness of free-living 625 striped mice in the harsh Succulent Karoo environment.

626

627

DATA AVAILABILITY STATEMEN

628

The data that support the findings of this study are available from the corresponding author upon reasonable request.

630

631

ORCID

632

Neville Pillay http://orcid.org/0000-0002-0778-726X

633

Tasmin Rymer https://orcid.org/0000-0002-9963-6345

634

635

\section{REFERENCES}

636

Abatan, O. I., Welch, K. B., \& Nemzek, J. A. (2008). Evaluation of saphenous venipuncture and modified tail-clip blood collection in mice. Journal of the American Association for Laboratory Animal Science, 47(3), 8-15.

Agarwal, P., Palin, N., Walker, S. L., \& Glasper, E. R. (2020). Sex-dependent effects of paternal deprivation and chronic variable stress on novel object recognition in adult California mice (Peromyscus californicus). Hormones and Behavior, 117, 104610. https://dx.doi.org/10.1016/j.yhbeh.2019.104610

Akkerman, S., Blokland, A., Reneerkens, O., van Goethem, N. P., Bollen, E., Gijselaers, H. J., Lieben, C. K. J., Steinbusch, H. W. M., \& Prickaerts, J. (2012). Object recognition testing: methodological considerations on exploration and discrimination measures. 
Bates, D., Maechler, M., Bolker, B., Walker, S., Christensen, R. H. B., Singmann, H., Dai, B, Scheipl, F., Grothendieck, G., Green, P., \& Fox, J. (2020). Package 'lme4'. https://cran.rproject.org/web/packages/lme4/lme4.pdf

Bee, M., Bernal, X., Calisi, R., Carere, C., Carter, T., Fuertbauer, L., Ha, J. C., Hubrecht, R., Jennings, D., Metcalfe, N.., Ophir, A. G., Ratcliffe, J. M., Roth II, T., Smith, A., Sneddon, L. \& Vitale, A. (2020). Guidelines for the treatment of animals in behavioural

Braun, K., \& Champagne, F. A. (2014). Paternal influences on offspring development: behavioural and epigenetic pathways. Journal of Neuroendocrinology, 26(10), 697-706. https://dx.doi.org/10.1111/jne.12174

Bredy, T. W., Lee, A. W., Meaney, M. J., \& Brown, R. E. (2004). Effect of neonatal handling and paternal care on offspring cognitive development in the monogamous California

Brooks, P. M. (1982). Aspects of the reproduction, growth and development of the fourstriped field mouse, Rhabdomys pumilio (Sparrman, 1784). Mammalia, 46(1), 53-64. https://dx.doi.org/10.1515/mamm.1982.46.1.53

Brown, R. E. (1993). Hormonal and experiential factors influencing parental behaviour in male rodents: an integrative approach. Behavioural Processes, 30, 1-28. https://dx.doi.org/10.1016/0376-6357(93)90009-G 
669 Cantoni, D., \& Brown, R. E. (1997). Paternal investment and reproductive success in the

670 California mouse, Peromyscus californicus. Animal Behaviour, 54, 377-386.

$671 \quad$ https://dx.doi.org/10.1006/anbe.1996.0583

672 Cavigelli, S. A., \& McClintock, M. K. (2003). Fear of novelty in infant rats predicts adult 673 corticosterone dynamics and an early death. Proceedings of the National Academy of $674 \quad$ Sciences, 100(26), 16131-16136. https://dx.doi.org/10.1073/pnas.2535721100

675 Clarke, F. M., \& Faulkes, C. G. (1997) Dominance and queen succession in captive colonies 676 of the eusocial naked mole-rat, Heterocephalus glaber. Proceedings of the Royal Society 677 of London B, 264, 993-1000. https://dx.doi.org/10.1098/rspb.1997.0137

678 Curley, J. P., Mashoodh, R., \& Champagne, F. A. (2011). Epigenetics and the origins of 679 paternal effects. Hormones and Behavior, 59, 306-314.

680 https://dx.doi.org/10.1016/j.yhbeh.2010.06.018

Dewsbury, D. A. (1985). Paternal behavior in rodents. American Zoologist, 25(3), 841-852. https://dx.doi.org/10.1093/icb/25.3.841

DeMartini, E. E. (1987). Paternal defence, cannibalism and polygamy: factors influencing the reproductive success of painted greenling (Pisces, Hexagrammidae). Animal Behaviour, 35, 1145-1158. https://dx.doi.org/10.1016/S0003-3472(87)80171-9

Elekonich, M. M., \& Robinson, G. E. (2000). Organizational and activational effects of hormones on insect behavior. Journal of Insect Physiology, 46, 1509-1515. https://dx.doi.org/10.1016/S0022-1910(00)00101-3

Fox, J., Weisberg, S., Price, B., Adler, D., Bates, D., Baud-Bovy, G., Bolker, B., Ellison, S., Firth, D., Friendly, M., Gorjanc, G., Graves, S., Heiberger, R., Krivitsky, P., Laboissiere, R., Maechler, M., Monette, G., Murdoch, D., Nilsson, H., Ogle, D., Ripley, B., Venables, W., Walker, S., Winsemius, D., Zeileis, A., \& R-Core (2020). Package 'car'. https://cran.r-project.org/web/packages/car/car.pdf 
694 Frazier, C. R., Trainor, B. C., Cravens, C. J., Whitney, T. K., \& Marler, C. A. (2006). Paternal behavior influences development of aggression and vasopressin expression in male California mouse offspring. Hormones and Behavior, 50(5), 699-707. https://dx.doi.org/10.1016/j.yhbeh.2006.06.035

Glasper, E. R., Hyer, M. M., \& Hunter, T. J. (2018). Enduring effects of paternal deprivation in California mice (Peromyscus californicus): behavioral dysfunction and sex-dependent alterations in hippocampal new cell survival. Frontiers in Behaivoral Neuroscience, 12, 20. https://dx.doi.org/10.3389/fnbeh.2018.00020

Gubernick, D. J., \& Teferi, T. 2000. Adaptive significance of male parental care in a monogamous mammal. Proceedings of the Royal Society of London B, 267(1439), 147-

Gubernick, D. J., Sengelaub, D. R., \& Kurz, E. M. (1993). A neuroanatomical correlate of paternal and maternal behavior in the biparental California mouse (Peromyscus 150. https://dx.doi.org/10.1098/rspb.2000.0979

712 Hardy, M. P., Gao, H-B., Dong, Q., Ge, R., Wang, Q., Chai, W. R, Feng, X., \& Sottas, C.

713 (2005). Stress hormone and male reproductive function. Cell Tissue Research, 322, 147153. https://dx.doi.org/10.1007/s00441-005-0006-2

715 Holbrook, G. L., \& Schal, C. (2004). Maternal investment affects offspring phenotypic 716 plasticity in a viviparous cockroach. Proceedings of the National Academy of Sciences USA, 101(5), 5595-5597. https://dx.doi.org/10.1073/pnas.0400209101 
Jia, R., Tai, F., An, S., Zhang, X., \& Broders, H. (2009). Effects of neonatal paternal deprivation or early deprivation on anxiety and social behaviors of the adults in mandarin voles. Behavioural Processes, 82(3), 271-278. https://dx.doi.org/10.1016/j.beproc.2009.07.006

Jones, M. A., Mason, G., \& Pillay, N. (2010). Early social experience influences the development of stereotypic behaviour in captive-born striped mice Rhabdomys. Applied Animal Behaviour Science, 123(1-2), 70-75. $\underline{\text { https://dx.doi.org/10.1016/j.applanim.2009.12.009 }}$

Jonsson, B., \& Jonsson, N. (2014). Early environment influences later performance in fishes. Journal of Fish Biology, 85, 151-188. https://dx.doi.org/10.1111/jfb.12432

Lehtinen, R. M., Green, S. E., \& Pringle, J. L. (2014). Impacts of paternal care and seasonal change on offspring survival: a multiseason experimental study of a Caribbean frog. Ethology, 120, 400-409. https://dx.doi.org/10.1111/eth.12215

Lenth, R., Singmann, H., Love, J., Buerkner, P., \& Herve, M. (2020). Package ‘emmeans'. https://cran.r-project.org/web/packages/emmeans/emmeans.pdf

Leshner, A. I. (1980). The interaction of experience and neuroendocrine factors in determining behavioral adaptations to aggression. Progress in Brain Research, 53, 427438. https://dx.doi.org/10.1016/S0079-6123(08)60081-3

Liu, D., Diorio, J., Tannenbaum, B., Caldji, C., Francis, D., Freedman, A., Sharma, S., Pearson, D., Plotsky, P. M., \& Meaney, M. J. (1997). Maternal care, hippocampal glucocorticoid receptors, and hypothalamic-pituitary-adrenal responses to stress. Science, 277(5332), 1659-1662. https://dx.doi.org/10.1126/science.277.5332.1659

Lueptow, L. M. (2017). Novel object recognition test for the investigation of learning and memory in mice. Journal of Visualized Experiments, 126, e55718. $\underline{\text { https://dx.doi.org/10.3791/55718 }}$ 
Ma, E., Lau, J., Grattan, D. R., Lovejoy, D. A., \& Wynne-Edwards, K. E. (2005). Male and female prolactin receptor mRNA expression in the brain of a biparental and a uniparental hamster, Phodopus, before and after the birth of a litter. Journal of Neuroendocrinology, 17, 81-90. https://dx.doi.org/10.1111/j.1365-2826.2005.01278.x

Mashoodh, R., \& Champagne, F. A. (2019). Chapter 6 - Paternal epigenetic inheritance. Transgenerational Epigenetics (Second Edition), 13, 107-133. https://dx.doi.org/10.1016/B978-0-12-816363-4.00006-7

Mackay, M., Rymer, T. L., \& Pillay, N. (2014). Separation at weaning from the family is stressful for naturally group-living, but not solitary-living, male African striped mice Rhabdomys. Stress, 17(3), 266-274. https://dx.doi.org/10.3109/10253890.2014.910762

Macrì, S., Adriani, W., Chiarotti, F., \& Laviola, G. (2002). Risk taking during exploration of a plus-maze is greater in adolescent than in juvenile or adult mice. Animal Behaviour, 64, 541-546. https://dx.doi.org/10.1006/anbe.2002.4004

McCarty, R., \& Southwick, C. H. (1977). Paternal care and the development of behavior in the southern grasshopper mouse, Onychomys torridus. Behavioral Biology, 19(4), 476490. https://dx.doi.org/10.1016/S0091-6773(77)91933-2

McGhee, K. E., \& Bell, A. M. (2014). Paternal care in a fish: epigenetics and fitness enhancing effects on offspring anxiety. Proceedings of the Royal Society of London B, 281, 20141146. https://dx.doi.org/10.1098/rspb.2014.1146

Moreno, J., Veiga, J. P., Cordero, P. J., \& Mínguez, E. (1999). Effects of paternal care on reproductive success in the polygynous spotless starling Sturnus unicolor. Behavioral Ecology and Sociobiology, 47, 47-53. https://dx.doi/org/10.1007/s002650050648

Outscharoff, W. Jnr, Helmeke, C., \& Braun, K. (2006). Lack of paternal care affects synaptic development in the anterior cingulated cortex. Brain Research, 1116(1), 58-63. https://dx.doi.org/10.1016/j.brainres.2006.07.106 
Oyegbile, T. O., \& Marler, C. A. (2005). Winning fights elevates testosterone levels in California mice and enhances future ability to win fights. Hormones and Behavior, 48, 259-267. https://dx.doi.org/10.1016/j.yhbeh.2005.04.007

Oyegbile, T. O., \& Marler, C. A. (2006). Weak winner effect in a less aggressive mammal: Correlations with corticosterone but not testosterone. Physiology \& Behavior, 89, 171179. https://dx.doi.org/10.1016/j.physbeh.2006.05.044

Perkeybile, A. M., Griffin, L. L., \& Bales, K. L. (2013). Natural variation in early parental care correlates with social behaviors in adolescent prairie voles (Microtus ochrogaster). Frontiers in Behavioral Neuroscience, 7, 21. https://dx.doi.org/10.3389/fnbeh.2013.00021

Pillay, N. (2000). Fostering in the African striped mouse: implications for kin recognition and dominance. Acta Theriologica, 45, 193-200.

Pillay, N., \& Rymer, T. L. (2015). Alloparenting enhances the emotional, social and cognitive performance of female African striped mice, Rhabdomys pumilio. Animal Behaviour, 99, 43-52. http://dx.doi.org/10.1016/j.anbehav.2014.10.003

Pillay, N., Rimbach, R., \& Rymer, T. (2016). Pre-and postnatal dietary protein deficiency influences anxiety, memory and social behaviour in the African striped mouse Rhabdomys dilectus chakae. Physiology \& Behavior, 161, 38-46. https://dx.doi.org/10.1016/j.physbeh.2016.04.015

Place, N. J., \& Kenagy, G. J. (2000). Seasonal changes in plasma testosterone and glucocorticosteroids in free-living male yellow-pine chipmunks and the response to capture and handling. Journal of Comparative Physiology B, 170, 245-251. https://dx.doi.org/10.1007/s003600050282

Prounis, G. S., Foley, L., Rehman, A., \& Ophir, A. G. (2015). Perinatal and juvenile social environments interact to shape cognitive behaviour and neural phenotype in prairie voles. 

https://dx.doi.org/10.1098/rspb.2015.2236

795

796

797

798

799

800

801

802

803

804

805

806

807

808

809

810

811

812

813

814

815

Raynaud, J., \& Schradin, C. (2014). Experimental increase of testosterone increases boldness and decreases anxiety in male African striped mouse helpers. Physiology \& Behavior, 129, 57-63. https://doi.org/10.1016/j.physbeh.2014.02.005

Raynaud, J., Müller, K., \& Schradin, C. (2012). Experimental increase of testosterone levels in free-ranging juvenile male African striped mice (Rhabdomys pumilio) induces physiological, morphological, and behavioral changes. General and Comparative Endocrinology, 178(1), 108-115. http://dx.doi.org/10.1016/j.ygcen.2012.04.028

Retana-Márquez, S., Bonilla-Jaime, H., Vázquez-Palacios, G., Martínez-García, R., \& Velázquez-Moctezuma, J. (2003). Changes in masculine sexual behavior, corticosterone and testosterone in response to acute and chronic stress in male rats. Hormones and Behavior, 44, 327-337. https://dx.doi.org/10.1016/j.yhbeh.2003.04.001

Ripley, B., Venables, B., Bates, D. M., Hornik, K., Gebhardt, A., \& Firth, D. (2020). Package 'MASS'. https://cran.r-project.org/web/packages/MASS/MASS.pdf

Robertson, I. C. (1998). Paternal care enhances male reproductive success in pine engraver beetles. Animal Behaviour, 56, 595-602. https://dx.doi.org/10.1006/anbe.1998.0816

Rymer, T. L., \& Pillay, N. (2011a). Transmission of parental care behavior in African striped mice, Rhabdomys pumilio. Journal of Experimental Zoology, 315(10), 631-638. https://dx.doi.org/10.1002/jez.712

Rymer, T. L., \& Pillay, N. (2011b). The influence of the early rearing environment on the development of paternal care in African striped mice. Ethology, 117(4), 284-293. https://dx.doi.org/10.1111/j.1439-0310.2011.01873.x 
816 Rymer, T. L., \& Pillay, N. (2013). Maternal care in the African striped mouse Rhabdomys

817 pumilio: a behaviorally flexible phenotype that is modified by experience.

818 Developmental Psychobiology, 55, 265-274. https://dx.doi.org/10.1002/dev.21020

819 Rymer, T. L., \& Pillay, N. (2018). An integrated understanding of paternal care in mammals:

820 lessons from the rodents. Journal of Zoology, 306(2), 69-76.

821 https://dx.doi.org/10.1111/jzo.12575

Rymer, T., Schradin, C., \& Pillay, N. (2008). Social transmission of information about novel food in two populations of the African striped mouse, Rhabdomys pumilio. Animal Behaviour, 76(4), 1297-1304. https://dx.doi.org/10.1016/j.anbehav.2008.06.014

Schoepf, I., \& Schradin, C. (2012). Better off alone! Reproductive competition and ecological constraints determine sociality in the African striped mouse (Rhabdomys pumilio). Journal of Animal Ecology, 81(3), 649-656. https://dxdoi.org/10.1111/j.1365$\underline{2656.2011 .01939 . x}$

$\underline{\text { Schradin, C. (2005). When to live alone and when to live in groups : ecological determinants }}$ of sociality in the African striped mouse (Rhabdomys pumilio, Sparrman, 1784). Belgian Journal of Zoology, 135(Supplement), 77-82.

Schradin, C. (2008). Differences in prolactin levels between three alternative male reproductive tactics in striped mice (Rhabdomys pumilio). Proceedings of the Royal Society of London B, 275(1638), 1047-1052. https://dx.doi.org/10.1098/rspb.2008.0004

835 Schradin, C., \& Anzenberger, G. (1999). Prolactin, the hormone of paternity. News in $836 \quad$ Physiological Sciences, 14(6), 223-231. https://dx.doi.org/10.1152/physiologyonline.1999.14.6.223

838 Schradin, C., \& Pillay, N. (2003). Paternal care in the social and diurnal striped mouse 839 (Rhabdomys pumilio): laboratory and field evidence. Journal of Comparative $840 \quad$ Psychology, 117(3), 317-324. https://dx.doi.org/10.1037/0735-7036.117.3.317 
841 Schradin, C., \& Pillay, N. (2004). The striped mouse (Rhabdomys pumilio) from the

842 succulent karoo, South Africa: a territorial group-living solitary forager with communal

843 breeding and helpers at the nest. Journal of Comparative Psychology, 118(1), 37-47.

$844 \quad$ https://dx.doi.org/10.1037/0735-7036.118.1.37

845 Schradin, C., \& Pillay, N. (2005). Demography of the striped mouse (Rhabdomys pumilio) in 846 the succulent karoo. Mammalian Biology, 70(2), 84-92. https://dx.doi.org/10.1016/j.mambio.2004.06.004

848 Schradin, C., König, B., \& Pillay, N. (2010). Reproductive competition favours solitary 849 living while ecological constraints impose group-living in African striped mice. Journal of Animal Ecology, 79(3), 515-521. https://doi.org/10.1111/j.1365-2656.2009.01651.x

Schradin, C., Scantlebury, M., Pillay, N., \& König, B. (2009). Testosterone levels in dominant sociable males are lower than in solitary roamers: physiological differences between three male reproductive tactics in a sociably flexible mammal. The American Naturalist, 173(3), 376-388. https://dx.doi.org/10.1086/596535

Schradin, C., Schneider, C., \& Lindholm, A. K. (2010). The nasty neighbour in the striped mouse (Rhabdomys pumilio) steals paternity and elicits aggression. Frontiers in Zoology, 7, 19. https://doi.org/10.1186/1742-9994-7-19

Schuurman T. (1980). Hormonal correlates of agonistic behavior in adult male rats. Progress in Brain Research, 53, 415-420. https://dx.doi.org/10.1016/S0079-6123(08)60079-5

860 Shin, S. Y., Han, S. H., Woo, R.-S., Jang, S. H., \& Min, S. S. (2016). Adolescent mice show anxiety- and aggressive-like behavior and the reduction of long-term potentiation in mossy Fiber-CA3 synapses after neonatal maternal separation. Neuroscience, 316, 221231. https://dx.doi.org/10.1016/j.neuroscience.2015.12.041

864 Smith, B. R., \& Blumstein, D. T. (2008). Fitness consequences of personality: a metaanalysis. Behavioral Ecology, 19, 448-455. https://dx.doi.org/10.1093/beheco/arm144 
Tasse, J. (1986). Maternal and paternal care in the rock cavy, Kerodon rupestris, a South American hystricomorph rodent. Zoo Biology, 5(1), 27-43. https://dx.doi.org/10.1002/zoo.1430050105

Vallée, M., Mayo, W., Dellu, F., Le Moal, M., Simon, H., \& Maccari, S. (1997). Prenatal stress induces high anxiety and postnatal handling induces low anxiety in adult offspring: correlation with stress-induced corticosterone secretion. Journal of Neuroscience, 17(7), 2626-2636. https://doi.org/10.1523/JNEUROSCI.17-07-02626.1997

Wang, J., Tai, F., Yan, X., \& Yu, P. (2012). Paternal deprivation alters play-fighting, serum corticosterone and the expression of hypothalamic vasopressin and oxytocin in juvenile male mandarin voles. Journal of Comparative Physiology A, 198(11), 787-796. $\underline{\text { https://dx.doi.org/10.1007/s00359-012-0748-8 }}$

Woodroffe, R., \& Vincent, A. (1994). Mother's little helpers: patterns of male care in mammals. Trends in Ecology and Evolution, 9(8), 294-297. https://dx.doi.org/10.1016/0169-5347(94)90033-7

Wright, H. W. Y. (2006). Paternal den attendance is the best predictor of offspring survival in the socially monogamous bat-eared fox. Animal Behaviour, 71(3), 503-510. https://dx.doi.org/10.1016/j.anbehav.2005.03.043

Wright, S. L., \& Brown, R. E. (2002). The importance of paternal care on pup survival and pup growth in Peromyscus californicus when required to work for food. Behavioural Processes, 60, 41-52. https://dx.doi.org/10.1016/S0376-6357(02)00101-8

Ziegler, T. E., Wegner, F. H., \& Snowdon, C. T. (1996). Hormonal responses to parental and nonparental conditions in male cotton-top tamarins, Saguinus oedipus, a New World primate. Hormones and Behavior, 30(3), 287-297. https://dx.doi.org/10.1006/hbeh.1996.0035 
891 TABLES

892 TABLE 1 Mean $( \pm$ SE) minutes engaged in three parental care behaviours by male and

893 female African striped mice (Rhabdomys pumilio) separately (biparental treatment) and

894 mothers alone (uniparental treatment). Rows with the same letters are not significantly

895 different (post hoc tests; see text)

\begin{tabular}{lrrc}
\hline & \multicolumn{3}{c}{ Treatment } \\
Behaviour & Father & Mother & Uniparental \\
Near & $42.26(4.41) \mathrm{a}$ & $27.42(2.33) \mathrm{b}$ & $38.79(1.64) \mathrm{b}$ \\
Groom & $3.15(5.43) \mathrm{a}$ & $3.46(3.04) \mathrm{a}$ & $14.54(5.36) \mathrm{b}$ \\
Huddle & $78.14(5.87) \mathrm{a}$ & $112.79(6.72) \mathrm{b}$ & $195.8(3.58) \mathrm{c}$ \\
\hline
\end{tabular}

896

897

898 
FIGURE 1 Timeline of events, starting from observations of parental care in biparental and uniparental treatment groups (PND 2-10), to tests of the resulting male offspring, which were tested in five experiments in three developmental life stages: juvenile (PND 25), sub-adult (PND 45-50) and adult (PND 80 - > 120).

905

906

FIGURE 2 Mean + SE (a) duration of time (s) spent by male African striped mice

907 (Rhabdomys pumilio) in the centre of the neutral arena at three different life stages; and (b) number of transitions made by male striped mice between the periphery and centre at three different life stages. Points show individual scores. Comparisons were made for each variable by treatment. Different letters for duration or time show significant post hoc treatment and age differences for time in the centre, and age difference only for transitions (see text).

913 FIGURE 3 Mean + SE frequency of (a) allogrooming, (b) sitting in close body contact, and

914 (c) aggression displayed by male African striped mice (Rhabdomys pumilio) at two different

915 life stages. Points show individual scores. Comparisons were made for each behaviour by

916 treatment and age. For each behaviour, different letters show significant post hoc treatment

917 and/or age differences (see text).

918

919 FIGURE 4 Mean + SE duration of time (s) spent exploring (a) two identical objects in the 920 training phase (Et), a novel and familiar object (Er), and absolute differences in duration of 921 time (s) spent exploring a novel object and sample object during the retention phase (Da), and

922 (b) proportion of time spent with novel object while exploring both objects ( $\mathrm{Nr}$ ) and in 923 relation to both objects $(\mathrm{Np})$ by African striped mouse males (Rhabdomys pumilio) in two 
924 treatments (biparental and uniparental). Points show individual scores. Comparisons were

925 made for each behaviour by treatment. For each variable, different letters show significant

926 post hoc treatment differences (see text).

927

928 FIGURE 5 Mean + SE alternation scores, arm entries and percentage (\%) alternation by

929 African striped mouse males (Rhabdomys pumilio) in two treatments (biparental and

930 uniparental). Points show individual scores. Comparisons were made for each behaviour by

931 treatment. For each variable, different letters show significant post hoc treatment age

932 differences (see text).

933

934 FIGURE 6 Mean + SE time (minutes) spent engaged in three paternal behaviours (time spent

935 near pups and grooming and huddling pups) by male African striped mice (Rhabdomys

936 pumilio) from two treatments (biparental and uniparental). Points show individual scores.

937 Comparisons were made for each behaviour by treatment. For each behaviour, different

938 letters show significant post hoc treatment age differences (see text). 